\title{
Retrocalcaneal bursitis in juvenile chronic arthritis
}

\author{
Cláudia Goldenstein-Schainberg, Carlos Homsi, Rosa Maria Rodrigues Pereira, \\ Wilson Cossermelli
}

\begin{abstract}
Retrocalcaneal bursitis has been described in various adult rheumatic diseases and septic bursitis unrelated to previous bursal disease has been reported in children. The case is reported here of a girl with juvenile chronic arthritis who developed non-septic retrocalcaneal bursitis; the diagnosis was suggested by a combination of clinical and radiographic studies and was confirmed by ultrasonography.
\end{abstract}

(Ann Rheum Dis 1992; 51: 1162-1163)

Retrocalcaneal bursitis or inflammation of the bursa between the calcaneus and the Achilles tendon (fig l) is characterised by posterior heel pain, prominence of the Achilles tendon just proximal to its insertion, soft tissue bulging at both sides of the tendon, and pain with dorsiflexion of the foot which compresses the bursa between tendon and bone. ${ }^{1}$ Retrocalcaneal bursitis has been described in various adult rheumatic diseases ${ }^{2-6}$ including rheumatoid arthritis (RA), ankylosing spondylitis, psoriatic arthritis, Reiter's syndrome, pseudogout, and gout. In a similar manner, retrocalcaneal bursitis should be found in children with rheumatic diseases. There is only one published report, however, describing an 11 year old boy with non-septic retrocalcaneal bursitis without any underlying associated disease, ${ }^{7}$ and a few reports on septic bursitis unrelated to previous bursal disease. ${ }^{89}$ We suspect that non-septic bursitis in children with collagen diseases is underreported and underdetected; some cases are probably misdiagnosed as arthritis or tenosynovitis alone. The case is reported here of a

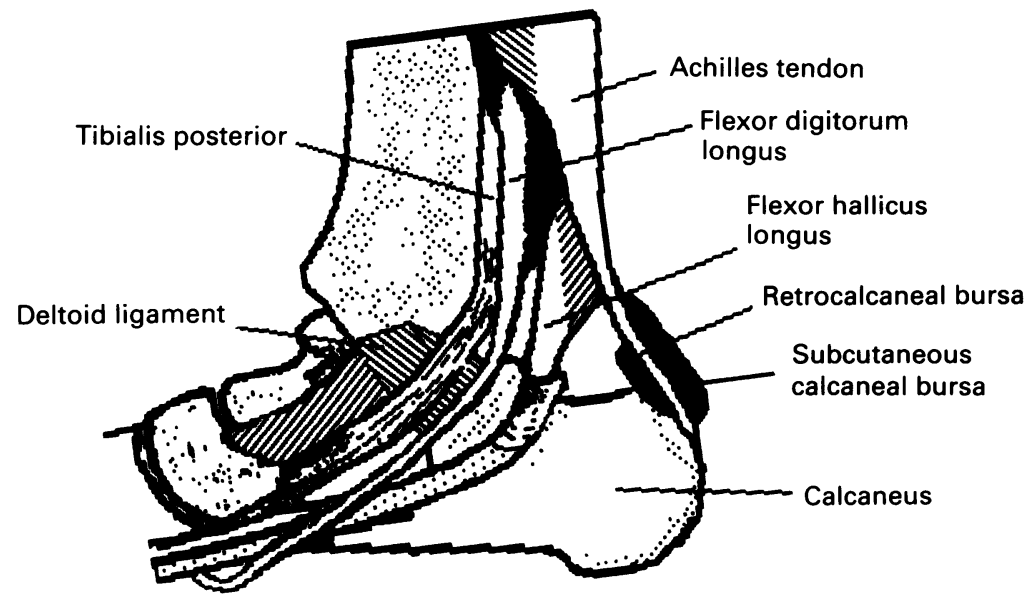

Figure 1 Anatomical diagram of the ankle. girl with polyarticular onset juvenile chronic arthritis who developed non-septic retrocalcaneal bursitis.

\section{Case report}

The patient, an 11 year old white girl, was three years old when she presented in 1981 to her doctor with arthritis of her wrists, knees, and ankles. Serological tests for antinuclear antibodies and rheumatoid factor were negative and radiographic studies were normal. She was diagnosed as having polyarticular onset juvenile chronic arthritis and was treated with intramuscular gold and aspirin until 1986 (cumulative dose $1550 \mathrm{mg}$ ). In September 1987 she was referred to our service presenting with pain, swelling, and stiffness of her knees and ankles. Physical examination showed tenderness and swelling of her knees and ankles with a full range of motion; laboratory results included negative rheumatoid factor, a positive speckled pattern of antinuclear antibodies in a titre of $1 / 200$, and increased levels of acute phase reactants. Radiographic studies of her ankles showed soft tissue swelling more evident on the right foot, without bone erosions or periosteal reaction. An ophthalmological examination was normal. Despite treatment with chloroquine at a dose of $5 \mathrm{mg} / \mathrm{kg} / \mathrm{day}$ and aspirin at a dose of $80 \mathrm{mg} / \mathrm{kg} / \mathrm{day}$, ankle pain persisted one year later. This was precipitated by walking and pressure from her shoes. Tenderness at the posterior surface of the calcaneus developed. The sacroiliac joints were not painful and Schober's test was negative. Radiographic studies showed bilateral soft tissue swelling and erosions of the posterosuperior aspect of the right calcaneus (fig 2) and ultrasonography (fig 3) showed bilateral Achilles tendonitis and retrocalcaneal bursitis. Computed tomography showed sacralisation of the last lumbar vertebra but not sacroiliac disease. The patient was treated with joint rest and indomethacin was introduced at a dose of $2 \mathrm{mg} / \mathrm{kg} /$ day with an improvement of symptoms within four months.

\section{Discussion}

Studies of foot deformities in children with juvenile chronic arthritis ${ }^{310}$ have shown that inflammation at the tendon, fascia, ligament, joint capsule attachment to bone (enthesitis), or synovium, and any type of deformity can occur in the foot of a child with juvenile chronic arthritis, including splayed feet with hallux valgus, clawing of the toes, plantar callosities, ankylosis, equinus deformity of the ankle, and 


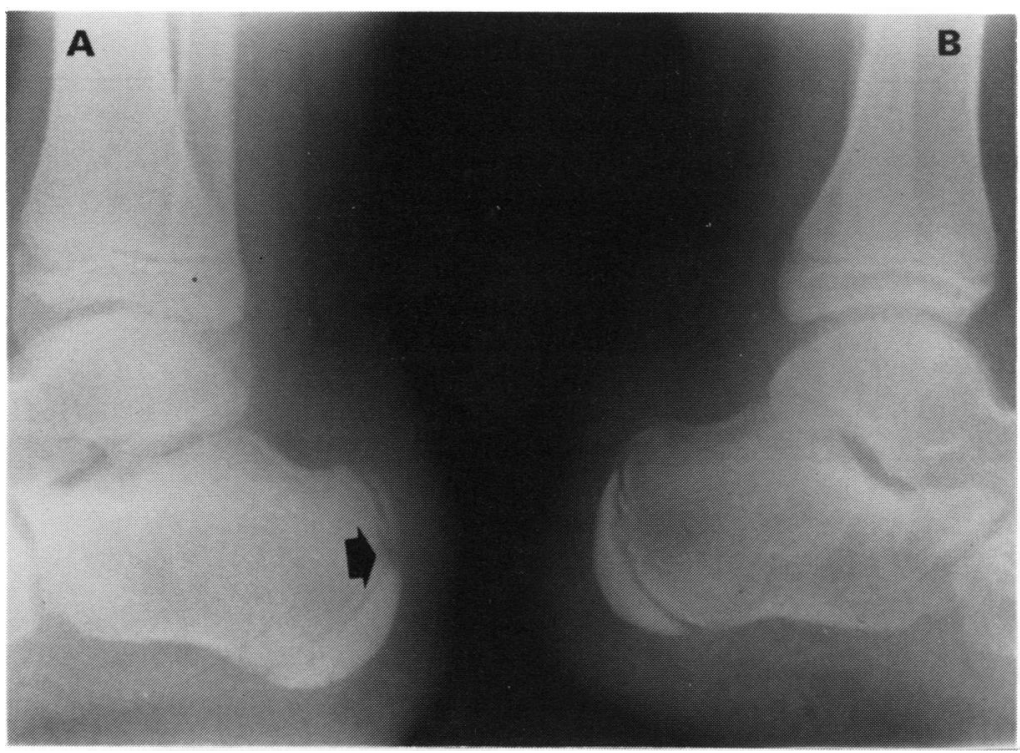

Figure 2 Lateral plane radiograph of right foot $(A)$ shows retrocalcaneal soft tissue swelling and calcaneal erosions (black arrow). Left foot $(B)$ shows only retrocalcaneal soft tissue swelling.

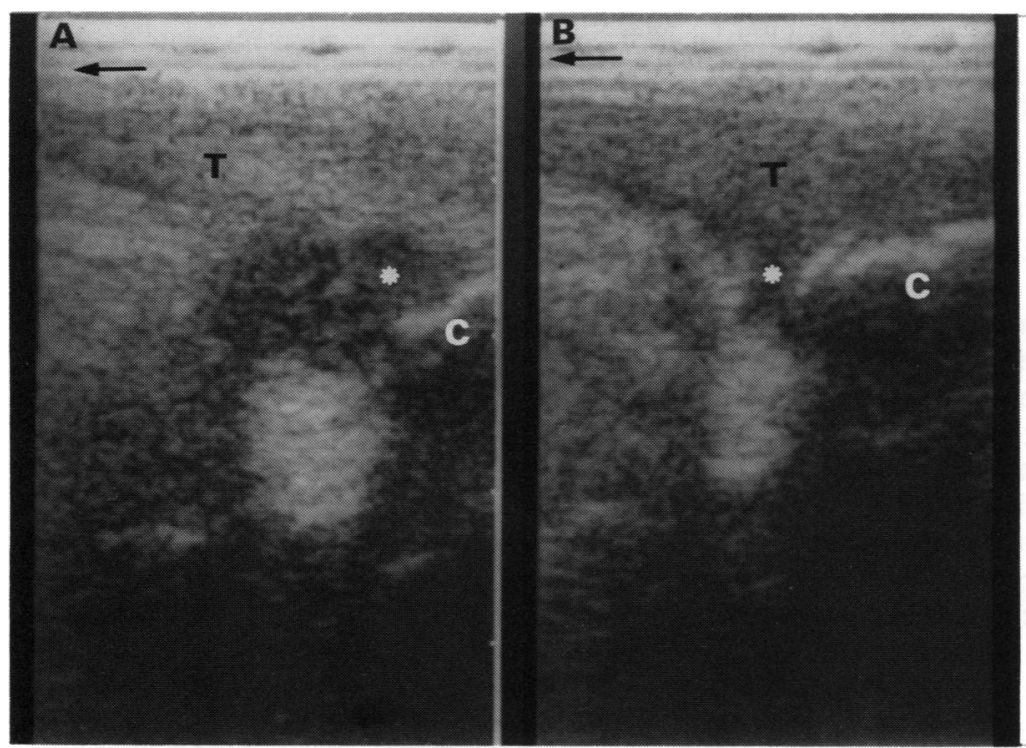

Figure 3 Sagittal sonogram with patient prone of right $(A)$ and left $(B)$ feet shows thickened retrocalcaneal bursa (asterisk), thickened Achilles tendon $(T)$ and posterior surface of calcaneus $(C)$. Black arrow points towards patient's head. Note that the lesions are more pronounced on the right foot $(A)$.

swelling around the ankle due to periostitis, tenosynovitis or synovitis of the ankle joint, or a combination of all of these. Sutro ${ }^{11}$ carried out a comparative radiographic and histological study of 50 heels obtained from amputated limbs and from necropsy including infants to elderly patients and found that the fat pad contiguous to the retrocalcaneal bursa may become altered by any inflammatory lesion. Bursitis has not been emphasised as a common finding in the foot of normal children or children with juvenile chronic arthritis, however.

As a deep bursa the retrocalcaneal bursa is closely related to the tendons and its pathology is usually a secondary event. In contrast to most deep bursa the retrocalcaneal bursa does not communicate with the closely related ankle and subtalar joints ${ }^{12}$ and often Achilles tendinitis and retrocalcaneal bursitis may coexist. ${ }^{1}$

Subcutaneous bursitis is relatively common in $\mathrm{RA}^{13}$ and may be observed in spondyloarthropathy, systemic lupus erythematosus, and scleroderma. ${ }^{12}$ On the other hand, although retrocalcaneal bursitis can occur in patients with $\mathrm{RA}$, as a result of trauma, or in calcium pyrophosphate deposition disease, it usually indicates Reiter's syndrome, psoriatic arthritis, or ankylosing spondylitis. ${ }^{4}$ It tends to occur in association with Achilles tendinitis and plantar fasciitis, and whether the inflammation starts in tendon, bursa, or in both structures simultaneously remains to be determined. ${ }^{12}$

In our patient retrocalcaneal bursitis was suggested by the combination of clinical and standard radiographic studies (fig 2) and was confirmed by ultrasonography (fig 3 ), which has been used in the evaluation of children with articular disorders ${ }^{14}$ and in the study of abnormalities of the Achilles tendon and adjacent bursae. ${ }^{15}$ The distinction between Achilles tendonitis and retrocalcaneal bursitis should be made because it has important implications for treatment. In addition to anti-inflammatory drugs and orthopaedic measures such as semirigid heel cups and appropriate shoes, local corticosteroid injections into the bursa offer benefits and relief of symptoms in most patients. It is suggested ${ }^{1}$ that the injection of steroids into the retrocalcaneal bursa also benefits the adjacent inflamed Achilles tendon.

We emphasise the usefulness of ultrasonography in allowing us to distinguish these two diseases and in the evaluation of children with other forms of soft tissue swelling.

I Canoso J J, Wohlgethan J R, Newberg A H, Goldsmith M R. Aspiration of the retrocalcaneal bursa. Ann Rheum Dis 1984 ; 43: $308-12$.

2 Bywaters E G L. Heel lesions of rheumatoid arthritis. Ann Rheum Dis 1954; 13: 42-51.

3 Vainio $K$. The rheumatoid foot. A clinical study with pathological and roentgenological comments. Ann Chir Gynaecol Suppl 1956; 45: 37, 90.

4 Resnick D, Feingold M L, Curd J, Niwayama G, Goergen $T$ G. Calcaneal abnormalities in articular disorders. Radiology 1977; 125: 355-66.

5 Gerster J C, Vischer T L, Bennanni A, Fallet G H. The painful heel: comparative study in rheumatoid arthritis ankylosing spondylitis, Reiter's syndrome and generalized osteoarthritis. Ann Rheum Dis 1977; 36: 343-8.

6 Canoso J J, Yood R A. Acute gouty bursitis: -report of 15

cases. Ann Rheum Dis 1971; 38: 326.
7 Nielson A L. Diagnostic and therapeutic point in retrocalcanean bursitis. FAMA 1921; 77: 463 .

8 Paisley J W. Septic bursitis in childhood. $\mathcal{J}$ Pediatr Orthop 1982; 2: 57-61.

9 Meyers S, Lonon W, Shannon K. Suppurative bursitis in early childhood. Pediatr Infect Dis 1984; 3: 156-8.

10 Rana N A. Juvenile arthritis of the foot. Foot Ankle 1982; 3: 2-11.

11 Sutro $\mathrm{C} J$. The os calcis, the tendo-achilles and the local bursae. Bull Hosp $\mathcal{F}$ Dis 1966; 27: 76-89.

12 Canoso J J. Bursal membrane and fluid. In: Cohen S, ed. Laboratory diagnostic procedures in the rheumatic diseases. 3rd ed. New York: Grune and Stratton, 1985; 55-76.

13 Golding D S, Stangler D A, Canoso J J. Rheumatoid subcutaneous bursitis. $\mathcal{F}$ Rheumatol 1981; 8: 974-8.

14 Goldenstein C, McCauley R, Troy M, Schaller J G, Szer I S. Ultrasonography in the evaluation of wrist swelling in children. I Rheumatol 1989; 16: 1079-87.

15 Mathieson J R, Connel D G, Cooperberg P L, Lloyd-Smith D R. Sonography of the achilles tendon and adjacent

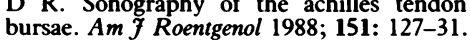

